\title{
Durable Complete Remission of a Brainstem Glioma Treated with a Combination of Bevacizumab and Cetuximab
}

\author{
Joan Manel Gasent Blesa ${ }^{a}$ Sara Blasco Mollá \\ María Fonfría Esparcia ${ }^{a}$ José Miguel Sempere Ortells ${ }^{e}$ \\ Miguel Peris Godoy ${ }^{b}$ Adrián Munilla Das ${ }^{d}$ \\ Balbino Mancheño Magan ${ }^{f}$ Mariano Provencio Pulla ${ }^{g}$ \\ Jose Luis Sanchez $^{\text {h }}$ Juan Bautista Laforga Canales ${ }^{c}$ \\ Vicente Alberola Candel ${ }^{a}$ \\ Departments of ${ }^{\mathrm{a}}$ Medical Oncology, ${ }^{\mathrm{b}}$ Internal Medicine, ${ }^{\mathrm{c}}$ Pathlogy and \\ ${ }^{d}$ Pharmacy, Hospital de Dénia, Marina Salud, Dénia, Departments of \\ ${ }^{\mathrm{e}}$ Immunology and ${ }^{\mathrm{f}}$ Organic Chemistry, Universitat d'Alacant, Alacant, \\ ${ }^{g}$ Department of Medical Oncology, Hospital Puerta de Hierro, Madrid, and \\ ${ }^{\mathrm{h}}$ Department of Ethics, Universidad Católica de València, València, Spain
}

\section{Key Words}

Glioma $\cdot$ Durable remission $\cdot$ Bevacizumab $\cdot$ Cetuximab

\begin{abstract}
Treatment of a relapsed glioma is a clinical challenge nowadays. New active treatments are required to treat these difficult diseases. Here we present a durable complete remission of a relapsed glioblastoma that has achieved a complete radiologic response with the combination of cetuximab and bevacizumab, in a third-line setting, that has offered a progression-free survival of 20 months. We consider here both potential mechanisms for the explanation of this result. First, the potential target of the cancer stem cells (CSCs) with these two antibodies, and second, the potential recruitment of the immune system to directly pursue the CSCs.
\end{abstract}

\section{Introduction}

Human brain tumors, both in pediatric cases and in adults, are a significant cause of morbidity and mortality. These tumors remain difficult to cure despite advances in surgery and adjuvant therapy techniques. Median survival in patients with

Joan Manel Gasent Blesa, MD, PhD Medical Oncologist

Hospital de Dénia, Marina Salud, Dénia, Partida de Beniadlà

ES-03700 Dénia (Spain)

E-Mail joanmagasent@telefonica.net 
glioblastoma is approximately 12 months after surgery and adjuvant radiotherapy [1]. The role of chemotherapy in gliomas after relapse is unclear [2-4]. There are no documented benefits from the use of chemotherapy on these fatal tumors [5, 6]. However, previously published reports on the use of irinotecan and bevacizumab in patients with recurrent supratentorial malignant gliomas showed that these chemotherapies led to occasional radiographic responses with marginal improvement in progression-free survival [7-9].

Accumulating evidence demonstrates that malignant tumors contain cancer stem cells (CSCs) $[10,11]$, and these CSCs constitute a minor fraction of a given tumor. CSCs are capable of self-renewal, potent differentiation, exclusive tumorigenicity and drug resistance $[12,13]$. The CSC hypothesis claims that, despite rigorous therapy, clinical relapse of tumors is inevitable as long as CSCs remain in the host [13]. This has been supported by observations in models of breast cancer [11], acute myeloid leukemia [14, 15], and brain tumors [16], where isolated CSCs initiated new tumors when injected into experimental animals.

One of the important issues for CSCs in gliomas is whether they contribute to the process of neovascularization, which includes angiogenesis and vasculogenesis. This is because stem cells produce higher levels of vascular endothelial growth factor (VEGF), which is inhibited by the VEGF-neutralizing antibody, bevacizumab [17]. Epidermal growth factor receptor (EGFR) has also been reported to be important to glioma CSCs, and it has been implicated in glioma aggressiveness, treatment unresponsiveness, and shortened survival [18].

In this paper, we report our experience with bevacizumab and cetuximab in an adult patient with progressive brainstem glioma.

\section{Case Report}

We reviewed the medical record of a patient from the Hospital de Denia - Marina Salud. The patient, a man, born in 1969, presented in March 2007 with progressive headaches, dizziness and dysgeusia. Magnetic resonance imaging (MRI) with contrast enhancement in a $5 \times 5 \times 5 \mathrm{~cm}$ ring demonstrated a right temporal mass of a cystic nature along with edema (ig. 1).

Total removal of the tumor was performed on March 3, 2007, and the tumor was histologically proven to be a glioblastoma multiforme (GBM). The patient underwent standard treatments of adjuvant radiotherapy ( $60 \mathrm{~Gy}$ in 6 weeks) and adjuvant chemotherapy with administration of temozolomide, first administered concomitantly with radiotherapy $\left(75 \mathrm{mg} / \mathrm{m}^{2} /\right.$ day), then administered sequentially $\left(150 \mathrm{mg} / \mathrm{m}^{2} /\right.$ day for 5 days in each cycle of 28 days, for 6 cycles).

MRI follow-up at 8 months after resection revealed suspicious signs of a local relapse in the surgical bed without areas of restricted diffusion. The hypometabolic lesion was followed until September 2008, when the patient suffered hemiparesis in the upper and lower extremities on the left side. MRI scans demonstrated new contrast-enhancing areas of an infiltrative tumor in the right temporal mass and corpus callosum (fig. 2).

The patient was then started on intravenous irinotecan administered once every 2 weeks for 3 cycles, but he did not exhibit any improvement. At this point, the patient came to our hospital for a second opinion. Because there is not a defined treatment for recurrent stages of glioblastoma, we discussed the option of using bevacizumab. Bevacizumab, either alone or in combination with chemotherapy, extends progression-free survival and has a steroid-sparing effect in glioblastoma patients relative to historical controls $[7,9,19]$. The patient refused to continue with irinotecan in any of the potential drug combinations. 
After weighing the options and considering the potential dependence of CSCs on VEGF and EGFR, we recommended treatment with a combination of $500 \mathrm{mg} / \mathrm{m}^{2}$ cetuximab and $10 \mathrm{mg} / \mathrm{kg}$ bevacizumab every two weeks. During administration of bevacizumab and cetuximab, the patient did not suffer from any relevant adverse events due to the drugs. The major side effects noted were a grade 2 acneiform skin reaction and dermatitis. The patient showed objective clinical improvement of his symptoms after only two cycles (fig. 3 ).

The patient continued to show dramatic clinical improvement. Interval MRIs showed continuing decreases in the degree of contrast enhancement ( fig. 4), and the patient was considered to be in complete radiological remission as of February 2011, when radiological relapse was documented, for a total of 20 months of progression-free survival ( fig. 5 ).

\section{Discussion}

GBM is a very aggressive primary brain tumor resulting in a short life expectancy for patients after diagnosis and with a grim prognosis despite maximal treatment [20]. The role of conventional chemotherapy in the treatment of diffusely infiltrative gliomas remains unclear. Furthermore, the effectiveness of chemotherapy after relapse is uncertain. It has been suggested that tumorigenicity and resistance to therapy might not be a feature of all cells in the bulk tumor mass, but rather a feature of a select population of cells with a stem-like phenotype [21], the CSCs. This select population of stem-like cells from human GBMs displayed potential pro-angiogenic activity, adhesion molecule expression and chemoresistance, all features likely to contribute to glioma relapse and progression. Based on these reasons, we used a combination of bevacizumab and cetuximab to directly target CSCs. Therefore, clinical improvement in our patient following bevacizumab and cetuximab combined therapy could be attributable on one side to a direct effect of both drugs on the tumor by respectively neutralizing the excess of VEGF secretion and by blocking the binding of EGF and other ligands to EGFR as well as by promoting downregulation of the receptor, mainly in the CSC subpopulation.

On the other side an additional immunomodulatory effect carried out by a synergistic action of both drugs aimed to fully eliminate residual CSC after chemotherapy should not be discarded. We suggest that binding of both antibodies to their targets could activate the complement system and would facilitate contact of opsonized tumor cells and molecules with granulocytes, macrophages and natural killer cells through the different Fc $\gamma \mathrm{R}$ displayed on their membranes thus increasing phagocytosis and promoting destruction of tumor cells through cell-to-cell contact mechanisms. A progressive increase of the proinflammatory environment around the tumor would completely activate more dendritic cells and other antigen-presenting cells, rendering them immunogenic and thus facilitating tumor antigen presentation to lymphocytes. This would progressively transform the immunosuppressive environment (tolerance) into a complete Th1 environment characterized by a significant increase of cellular immunity necessary for a complete tumor removal, including CSC. A decrease of the function and/or number of regulatory T cells (Treg) as a result of a dominant proinflammatory environment might also contribute to this positive response against the tumor.

We recommend future research to be done with these two drugs in this type of difficult clinical situations. 


\section{Disclosure Statement}

The authors declare no conflict of interest.

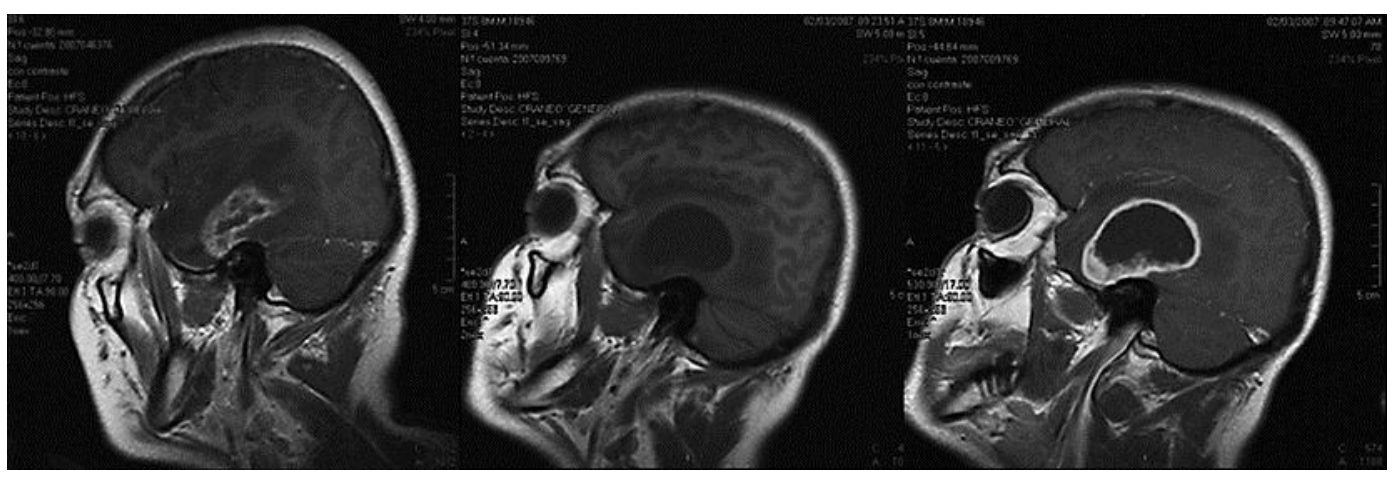

Fig. 1. MRI March 2007. Initial diagnosis.

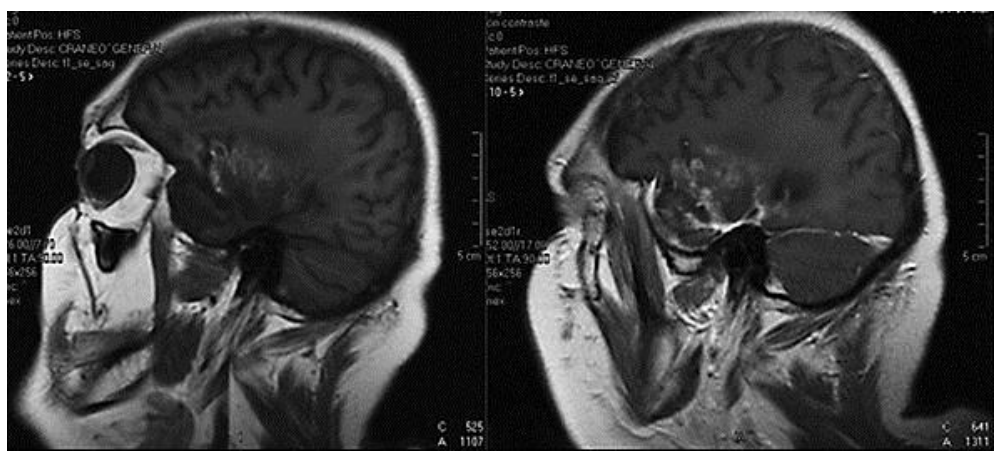

Fig. 2. MRI September 2008.

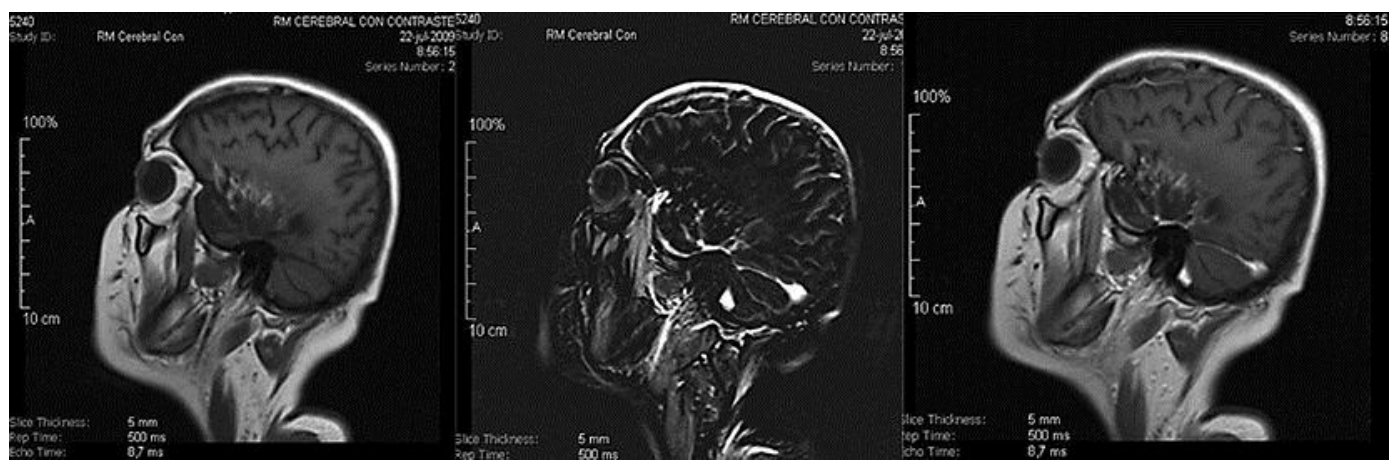

Fig. 3. MRI July 2009. 


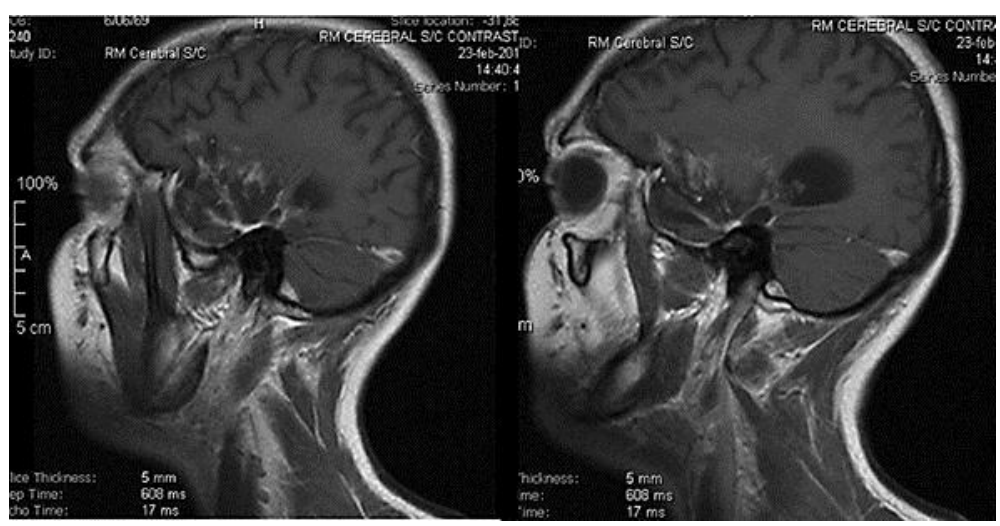

Fig. 4. MRI February 2010.

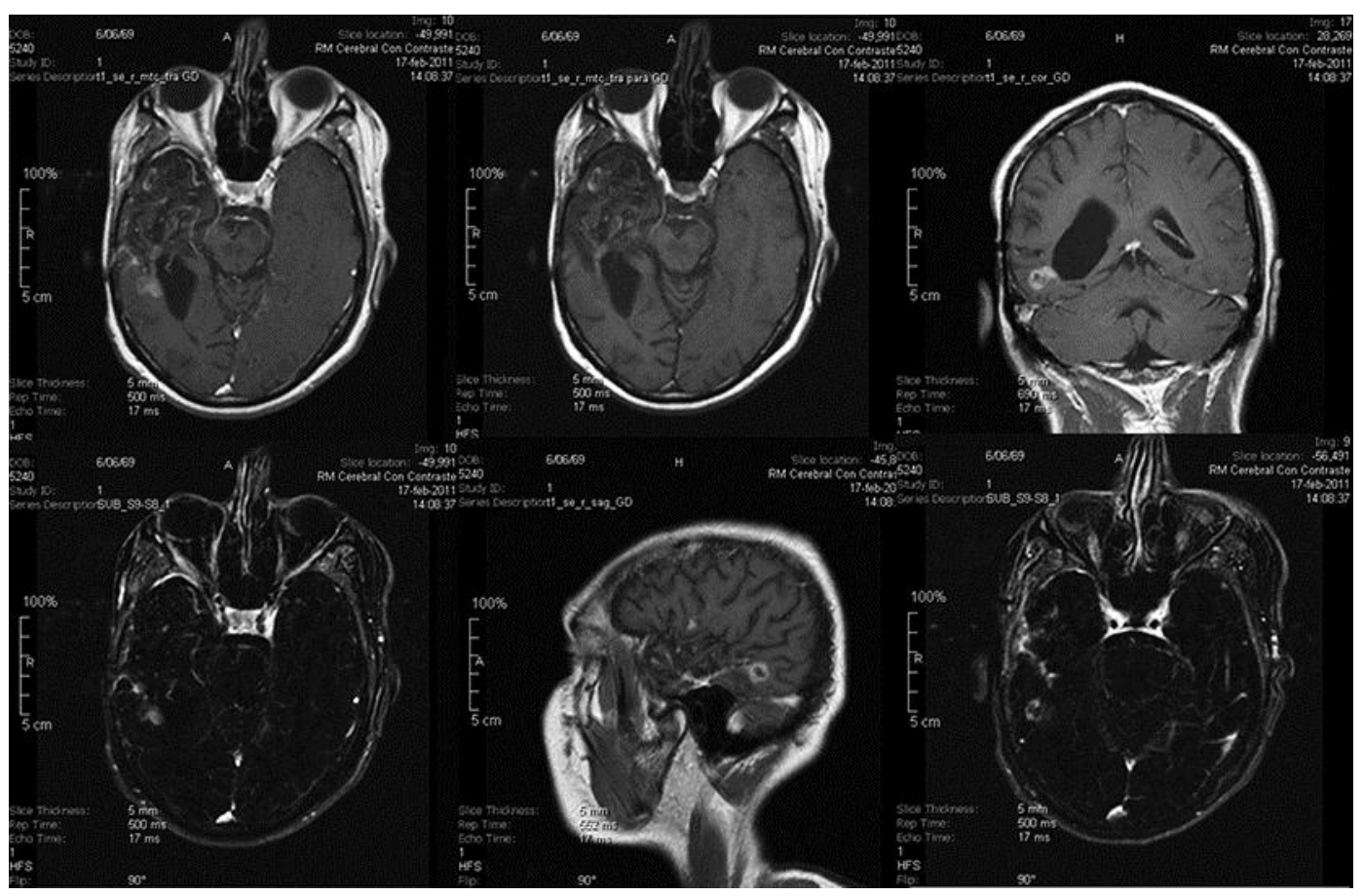

Fig. 5. MRI at relapse. February 2011. 


\section{References}

1 Salmaggi A, Boiardi A, Gelati M, et al: Glioblastoma-derived tumorospheres identify a population of tumor stem-like cells with angiogenic potential and enhanced multidrug resistance phenotype. Glia 2006;54:850-860.

2 Freeman CR, Perilongo G: Chemotherapy for brain stem gliomas. Childs Nerv Syst 1999;15:545-553.

3 Shuper A, Kornreich L, Loven D, Michowitz S, Schwartz M, Cohen IJ: Diffuse brain stem gliomas. Are we improving outcome? Childs Nerv Syst 1998;14:578-581.

-4 Bouffet E, Khelfaoui F, Philip I, Biron P, Brunet-Mentigny M, Philip T: High-dose carmustine for highgrade gliomas in childhood. Cancer Chemother Pharmacol 1997;39:376-379.

5 Allen JC, Siffert J: Contemporary chemotherapy issues for children with brainstem gliomas. Pediatr Neurosurg 1996;24:98-102.

-6 Wolff JE, Westphal S, Molenkamp G, Gnekow A, Warmuth-Metz M, Rating D, Kuehl J: Treatment of paediatric pontine glioma with oral trophosphamide and etoposide. Br J Cancer 2002;87:945-949.

>7 Vredenburgh JJ, Desjardins A, Herndon JEII, Dowell JM, Reardon DA, Quinn JA, Rich JN, Sathosumetee S, Gururangan S, Wagner M, Bigner DD, Friedman AH, Friedman HS: Phase II trial of bevacizumab and irinotecan in recurrent malignant glioma. Clin Cancer Res 2007;13:1253-1259.

-8 Vredenburgh JJ, Desjardins A, Herndon JEII, Marcello J, Reardon DA, Quinn JA, Rich JN, Sathosumetee S, Gururangan S, Sampson J, Wagner M, Bailey L, Bigner DD, Friedman AH, Friedman HS: Bevacizumab plus irinotecan in recurrent glioblastoma multiforme. J Clin Oncol 2007;25:4722-4729.

-9 Cloughesy TF, Prados MD, Wen PY, Mikkelsen T, Abrey LE, Schiff D, Yung WK, Maoxia Z, Dimery I, Friedman HS: A phase II, randomized, non-comparative clinical trial of the effect of bevacizumab (BV) alone or in combination with irinotecan (CPT) on 6-month progression free survival (PFS6) in recurrent, treatment-refractory glioblastoma (GBM). J Clin Oncol 2008;26:91s (abstr 2010b).

10 Galli R, Binda E, Orfaneli U: Isolation and characterization of tumorigenic, stem-like neural precursors from human glioblastoma. Cancer Res 2004;64:7011-7012.

11 Al-Hajj M, Wicha MS, Benito-Hernandez A, Morrison SJ, Clarke MF: Prospective identification of tumorigenic breast cancer cells. Proc Natl Acad Sci USA 2003;100:3983-3988.

$\checkmark 12$ Singh SK, Clarke ID, Hide T, Dirks PB: Cancer stem cells in nervous system tumors. Oncogene 2004;23:7267-7273.

13 Dean M, Fojo T, Bates S: Tumour stem cells and drug resistance. Nature 2005;5:275-284.

14 Blair A, Hogge DE, Ailles LE, Lansdorp PM, Sutherland HJ: Lack of expression of Thy-1 (CD90) on acute myeloid leukemia cells with long-term proliferative ability in vitro and in vivo. Blood 1997;89:31043112.

15 Bonnet D, Dick JE: Human acute myeloid leukemia is organized as a hierarchy that originates from a primitive hematopoietic cell. Nat Med 1997;3:730-737.

16 Hope KJ, Jin L, Dick JE: Acute myeloid leukemia originates from a hierarchy of leukemic stem cell classes that differ in self-renewal capacity. Nat Immunol 2004;5:738-743.

17 Yao XH, Ping YF, Chen JH, et al: Glioblastoma stem cells produce vascular endothelial growth factor by activation of a G-protein coupled formylpeptide receptor FPR. J Pathol 2008;215:369-376.

18 Murat A, Migliavacca E, Gorlia T, et al: Stem cell-related 'self-renewal' signature and high epidermal growth factor receptor expression associated with resistance to concomitant chemoradiotherapy in glioblastoma. J Clin Oncol 2008;26:3015-3024.

19 Batchelor TT, Sorensen AG, di Tomaso E, et al: AZD2171, a pan-VEGF receptor tyrosine kinase inhibitor, normalizes tumor vasculature and alleviate edema in glioblastoma patients. Cancer Cell 2007;11:83-95.

20 Stupp R, Mason WP, Van der Bent MJ, et al: Radiotherapy plus concomitant and adjuvant temozolomide for glioblastoma. N Engl J Med 2005;352:987-996.

21 Galli R, Gritti A, Bonfanti L, et al: Neuronal Stem Cells. Circulation Research 2003;92:598. 